\title{
BMJ Open Studying Impact of Nutrition on Growth (SING): a prospective cohort for comparing the health outcomes of young children with the dietary quality score
}

\author{
Albert Lee, ${ }^{1,2}$ Calvin Ka-man Cheung, ${ }^{1}$ Kenneth Lo, ${ }^{1,2}$ Vera Mei-wan Keung, ${ }^{1}$ \\ Lancelot Wai-ho Mui, ${ }^{2}$ Wilson W S Tam ${ }^{3}$
}

To cite: Lee A, Cheung CK, Lo K, et al. Studying Impact of Nutrition on Growth (SING): a prospective cohort for comparing the health outcomes of young children with the dietary quality score. BMJ Open 2017;7:e018380. doi:10.1136/ bmjopen-2017-018380

- Prepublication history for this paper is available online. To view please visit the journal online (http://dx.doi.org/10. 1136/bmjopen-2017-018380).

Received 28 June 2017 Revised 11 0ctober 2017 Accepted 12 October 2017

CrossMark

${ }^{1}$ Centre for Health Education and Health Promotion, The Chinese University of Hong Kong, Lek Yuen Health Centre, Shatin, Hong Kong

${ }^{2} \mathrm{JC}$ School of Public Health and Primary Care, The Chinese University of Hong Kong, Shatin, Hong Kong

${ }^{3}$ Alice Lee Centre for Nursing Studies, Yong Loo Lin School of Medicine, National University of Singapore, Singapore

Correspondence to Professor Albert Lee; alee@cuhk.edu.hk

\section{ABSTRACT}

Introduction This study aims to explore the prospective association between the dietary quality (DQ) of preschoolers and their health status in Hong Kong, with the body mass index as the main outcome variable.

Methods and analysis This prospective cohort study has recruited 3539 children aged between 2 and 4 years old, with a follow-up period of 4 years. Their diet was reported by their parents by a 3-day food diary, and their body weight and height were measured yearly with standardised instruments. Questionnaires were administered to parents to acquire information of the children's prenatal development and dietary intake before their age of 2 years and of their baseline lifestyle and family backgrounds. The DQ was measured by the Healthy Eating Index as a continuous scale, while the exposure was defined as having a higher dietary quality score. Data were analysed using SPSS V.24. Linear and logistic regressions were used to examine the association of those predictive factors to the outcomes. Generalised estimating equations will be used to examine the longitudinal changes of the outcomes. A pilot study has been conducted, the preliminary results from which are presented in this cohort profile.

Ethics and dissemination This study has been approved by the Joint Chinese University of Hong Kong and New Territory East Cluster Clinical Research Ethics Committee (CREC Ref No: 2013-632). Written informed consent was obtained from all subjects. The results will be published in due course.

\section{INTRODUCTION}

\section{Description of the condition}

Association between early-life nutrition and long-term health has been raised for decades. $^{1-3}$ Numerous studies have been reported the associations between early-life nutrition and normal growth and development (bone development, ${ }^{4}$ immune system ${ }^{5}$ and reproductive system ${ }^{6}$ ), acute disease $\left(\right.$ allergy $^{7}$ ) and chronic diseases (obesity ${ }^{8}$ and breast cancer ${ }^{9}$ ) and so on. For instance,
Strengths and limitations of this study

- Random sampling with reasonably large size ensuring generalisability.

- Validated tools minimising measurement errors.

- Self-reporting tools suffering from recall and social desirable bias.

several clinical trials have demonstrated that the intake of calcium and dairy products augments the bone mineral density in children. ${ }^{10}$ Although there were less evidence generated from intervention studies, adequate vitamin D intake could prevent muscle weakness among paediatric population. ${ }^{11}$

Epidemiological and animal studies have revealed that the risk of metabolic syndrome is elevated after exposure to suboptimal nutrition during crucial periods of development. ${ }^{1}$ Lim et al ${ }^{12}$ further highlighted the significance of potential risk factors to which children are exposed during early life and the global burden of non-communicable diseases. Adair et al suggested interventions to increase birth weight and linear growth during the first 2 years of life; such interventions are likely to result in substantial gains in height and schooling, with more protection from development of adult chronic diseases. ${ }^{13}$

Nevertheless, it has been reported that rapid weight gain in the first 2 years of life is related to an increased risk of obesity ${ }^{14}$ and insulin resistance in later life. ${ }^{15}$ Such a phenomenon, referred to as the catch-up dilemma, has drawn attention to the potential risks and benefits of faster early growth. ${ }^{13} 1617$ The faster weight gain after 
2 years of age has little benefit, and weight gain after midchildhood can result in adverse effects in terms of risk factors of cardiovascular diseases. ${ }^{13}$ In a review on early life origins of chronic non-communicable diseases, Wang et $a l^{18}$ have highlighted two findings. First, many current interventions on unhealthy eating and weight control have been on lifestyle modification later on in life, thus neglecting the difficulty of neuroendocrine programming to return to the original set point. Second, the modulation of perinatal and early postnatal environments would avoid adverse developmental programming of the neuroendocrine system that leads to obesity later on in life.

Compensation consumption of high energy density food among preschoolers can result in the suboptimal intake of recommended food groups, as shown by a study in Hong Kong. ${ }^{19}$

\section{The importance of this cohort study}

Bhutta $^{2}$ has called for cohort studies on elements of child development, education and employment as outcomes and as crucial future investments that will enable an improved estimation of the effect on human capital. Recent studies have advanced the understanding of the application of neurobiology to food addiction and obesity; therefore, multilevel interventions beyond simple behavioural approaches are necessary in the examination of the biochemical effects of complex interventions. ${ }^{20}$ A cohort study in the USA revealed that factors in early life are associated with children's body mass index (BMI) at 8 years of age, ${ }^{21}$ whereas a recent review reported that childhood obesity is a predictor of adult obesity. ${ }^{3}$

Aside from these factors, parents have critical roles in their children's development during the early years. Arredondo et $a l^{22}$ revealed that many studies had reported the relationship between parental control styles and children's consumption of healthy food, as well as the amount of consumption. An authoritarian parenting style was also associated with being overweight in early childhood, as early as the first grade. ${ }^{23}$ Many studies in Hong Kong focused on the effects of the parenting style on adolescents, ${ }^{24-28}$ but no study has elucidated the effects of the parenting style on physical health.

Although the use of the cohort design has numerous advantages in providing strong evidence on the causal relationship between potential risks or protective factors and various health outcomes, some practical difficulties, such as the prerequisite of large sample sizes and long follow-up periods, limit its use. ${ }^{29}$ To our knowledge, two community cohorts are currently used in Hong Kong: the FAMILY cohort ${ }^{30}$ and 'Children of 1997' birth cohort. ${ }^{31}$ The former focuses on happiness, harmony and health of families, ${ }^{32-34}$ whereas the latter focuses on the effect of the first 18 months of life on the children's health status. $^{313536}$
The birth cohort was established in 1997, and the breastfeeding practices, nutritional patterns and lifestyle status have changed over time. ${ }^{3738}$ A knowledge gap also exists in terms of the impact of the nutritional patterns and lifestyle practice on the health and growth of preschoolers. Therefore, both prospective and retrospective studies on children starting early childhood education should be designed to analyse the following: the impacts of psychosocial and economic factors during the first 1000 days of life on health and nutritional status, the long-term effect of nutrition on health, functional status and wellbeing, and human capital development mediated by sociodemographic factors.

\section{OBJECTIVES}

Given the lack of large studies on a cohort of children from kindergarten to primary school in a Chinese population, this study aims to provide comprehensive and reliable data that can be used to describe and understand the physical and mental health development of children during early schooling and how their early exposures relate to their later development.

\section{Primary objective}

To investigate the effects of exclusive breastfeeding in infancy on obesity rates among children at the age of 5 years.

\section{Secondary objectives}

To determine:

1. The dietary and nutritional intakes of preschool-aged children longitudinally.

2. The correlation between early nutritional intake and childhood obesity.

3. The influence of school and home environment (physical and social) on childhood health and well-being, as well as nutritional status and development.

4. The correlation between suboptimal growth and nutrition status and factors such as dietary pattern, parenting skills, health literacy of parents, household environment and suboptimal breast feeding.

5. The association of parenting styles with being overweight and nutritional intake.

\section{COHORT DESCRIPTION}

\section{Study design}

This study is a prospective cohort study. ${ }^{39}$ The overall approach of reporting the study is consistent with the Strengthening the Reporting of Observational Studies in Epidemiology statement. ${ }^{40}$

\section{Settings}

Recruitments were conducted in local kindergartens and nurseries, that is, schools that provide normal education to children aged 2-5 years in Hong Kong. 


\section{Inclusion criteria}

Eligible subjects were children aged 2-4 years in local kindergartens and nurseries at the time of recruitment and their parents.

\section{Sampling}

Cluster sampling, in which each kindergarten or nursery was considered as a cluster, was used in this study. ${ }^{41}$ A full list of kindergartens and nurseries in Hong Kong, extracted from the Education Bureau of the Hong Kong SAR Government, ${ }^{42}$ was stratified into the 18 districts in Hong Kong. A random number was generated using the 'randbetween' function in MS Excel 2010 for each kindergarten and nursery, and then schools were selected according to the magnitude of the assigned random numbers. The number of schools recruited in each district was determined by the sample size estimation as outlined below.

\section{Procedure}

The principals of the selected clusters were contacted from late 2014 to early 2015 for approval in the study participation. With their consents, all parents with their children studying in the respective kindergartens and nurseries were invited to participate. Since the study involved numerous schools and recruitment was started in the middle of the academic year 2014-2015, that is, January 2015, in order to match the yearly plan of some schools, most of their recruitment were postponed until the first term of the academic year 2015-2016, that is, September-December 2015; therefore, the subjects were recruited at different times throughout the year, with the majority being recruited during September-December 2015. After the written consent from the parents was obtained, their children underwent baseline assessment of parameters reflecting different outcomes.

\section{Exposure}

Exposure was defined as exclusive breast feeding (EBF) for 4 months or longer; this information was collected from the baseline questionnaire. Other exposures included inadequate intake or excessive consumption of particular nutrients (energy intake, protein, total fat, carbohydrates, sodium and calcium) according to the respective cut-offs, ${ }^{43-45}$ and the overall dietary quality derived from the Healthy Eating Index (HEI). ${ }^{46}$

\section{Sample size estimation}

Given that the prevalence of EBF has risen from $6 \%$ in 1997 to $14.8 \%$ in $2010,{ }^{47}$ we expected that the prevalence for EBF would be approximately $15 \%$. Thus, the ratio of EBF children to non-EBF ones would be approximately 15:85 or $3: 17$.

It has been reported that short-term EBF (fewer than 4 months) was associated with obesity in children aged 5 years old $(\mathrm{OR}=1.44 ; 95 \%$ CI 1.00 to $2.07 ; \mathrm{P}=0.050) .{ }^{48} \mathrm{As}$ the obesity problem has become more severe, we would expect a larger difference in the prevalence of obesity between the EBF group and the non-EBF at the end of the study period. Assuming the $\mathrm{OR}=1.9$ and a level of significance of $5 \%$ with $\sim 80 \%$ power, the sample size required to detect the difference would be 420 for the EBF group and 2800 for the non-EBF group, given the 3:17 ratio. Therefore, 3280 participants would be needed at the end of the 4-year study period. Given a $2.5 \%$ annual dropout rate, the sample size needed at the beginning of the study would be around 3539. According to the Education Bureau, the total number of prenursery (ie, schools available for children aged 2-3 years) children in the 2012-2013 academic years was $54829 .{ }^{49}$ Therefore, the suggested sample size could cover approximately $6.5 \%$ of the children at that age. With an assumption that there are 20-30 prenursery children per kindergarten and nursery, approximately 140 kindergartens and nurseries would be required.

\section{Outcome measurements}

Measurements included three baseline components: questionnaires, food diaries and physical measurements. Follow-up questionnaires and physical measurements would be collected annually after the baseline data collection. Details of the baseline components are described below.

\section{Questionnaire}

The children's parents were invited to fill the questionnaires and, on completion, returned them to the researcher. Both Chinese and English versions were available. There were three sections in the questionnaire on baseline components: section A concerns the children's prenatal development, section B concerns their dietary intake from birth to 2 years old and section C concerns their lifestyles and family backgrounds.

\section{Prenatal development}

There were nine questions on the children's prenatal development including their delivery mode, weeks of gestation, parental drinking and smoking status, maternal health conditions and mother's weight gain during pregnancy. The weights of the children at birth were also asked.

\section{Dietary intake from birth to $\mathbf{2}$ years old}

A total of 24 questions were used to examine the children's dietary intake from birth to 2 years old. The first five questions revolved around the breastfeeding practice when the children were younger than 1 year old, whereas the next four questions revolved around the formula milk feeding practice up to 18 months old. Questions 10-14 collected information of when and which kind of solid food had been consumed by the children since birth. Questions 15-21 enquired about the feeding practice on non-infant formula milk, Chinese herbal or botanical preparation drinks and nutritional supplements. Questions 22-24 assessed the frequency of consumption of commercial baby food (commercially prepared pureed food for babies, baby biscuits and desserts) and prepackaged or processed food of the subjects since 
Table 1 Demographic features of the participants at the end of recruitment $(n=3223)$

\begin{tabular}{ll}
\hline Characteristic & $\begin{array}{l}\text { Frequency (\%)/ } \\
\text { mean } \pm \text { SD* }^{*}\end{array}$ \\
\hline Child age (in years)† & $3.38 \pm 0.45$ \\
\hline Aged 2 & $588(18.2)$ \\
\hline Aged 3 & $2402(74.5)$ \\
\hline Aged 4 & $198(6.1)$ \\
\hline Non-response & $35(1.1)$ \\
\hline Children's gender $\ddagger$ & \\
\hline Male & $1669(51.8)$ \\
\hline Female & $1522(47.2)$ \\
\hline Non-response & $32(1.0)$ \\
\hline Main caregiver(s) (multiple selection) & \\
\hline Father & $2906(90.1)$ \\
\hline Mother & $3065(95.1)$ \\
\hline Maid & $889(27.6)$ \\
\hline
\end{tabular}

Breastfeeding practice (multiple

selection)

Breast fed at early stages, then fed 1258 (39.0) with formula milk

Fed with both breast milk and formula 897 (27.8) milk

\begin{tabular}{ll}
$\begin{array}{l}\text { Breast fed since birth and no formula } \\
\text { milk was fed }\end{array}$ & $432(13.4)$ \\
\hline $\begin{array}{l}\text { Fed with formula milk since birth and } \\
\text { did no adopt breast feeding }\end{array}$ & $617(19.1)$ \\
$\begin{array}{l}\text { Current habit of picky eating (multiple } \\
\text { selection) }\end{array}$ \\
\hline Rice & $264(8.2)$ \\
\hline Vegetables & $845(26.2)$ \\
\hline Fruit & $205(6.4)$ \\
\hline Meat & $383(11.9)$ \\
\hline Fish & $207(6.4)$ \\
\hline Egg & $228(7.1)$ \\
\hline Milk & $156(4.8)$ \\
\hline Water & $268(8.3)$ \\
\hline
\end{tabular}

*The total percentage may not equal to $100 \%$ due to non-response or multiple selection questions.

$\dagger$ Non-response originated from parents who did not report the birthdate of their children.

$\ddagger$ Non-response originated from children who have not undergone anthropometric measurements.

the introduction of solid food to the children aged 3 years old. Commercial baby food were categorised into different groups, including fruits and vegetables, grains, meats, beverages and snacks. The frequency of consumption ranged from 'None' to ' $>4$ times per week'.

\section{Lifestyle and family background}

The 22 questions in this section were divided into two parts. The first part included questions related to the children's lifestyles and habits, including the number of siblings, whom they live with, primary carers, sleep patterns, dental practice, activities and general health status. Most questions were in the multiple-choice format, except that the sleep duration was calculated by the difference in reported bedtime and wake time. Items assessing dental practice included whether the children brushed their teeth on their own or needed assistance from parents and the frequency of teeth-brushing per day. Questions on activities were open-ended for parents to report the types, duration and frequency of extracurricular activities or hobby classes in which the children were involved. Their general health status was assessed by a single-item question on the times that children required consultation of a doctor. The second part of the section enquired about the family background of the children including the type of housing and information concerning their parents such as the working status, occupation, education level, smoking status, birthday, weight, height and monthly household income.

\section{Food diary}

A 3-day food diary for recording the children's dietary intake was distributed to the parents, alongside the questionnaire. The parents were advised to include two weekdays and oneweekend for the 3-day period and to write down the food items and portions that their children consumed right after each meal. A standard medium bowl and an independent instruction booklet named the Children's Food Photo Book with photographs of food in actual sizes were provided to aid them in filling the food diary. They were also encouraged to take digital photos of the food as supplementary information for the researchers' references. Samples of the food diary and instructional booklet are attached. As for the children's meals during school time, parents were notified of the 2 weekdays when teachers would keep records of food intake of the participating children in school. The researchers also acquired the menus from schools directly as supplementary information for the food diary.

\section{Anthropometric assessment}

The height of the children was measured without shoes to the nearest $0.1 \mathrm{~cm}$ with a portable stadiometer (SECA 213), and the weight was measured without shoes to the nearest $0.1 \mathrm{~kg}$, using a digital calibrated floor scale (Tanita model HD-662). BMI was calculated in $\mathrm{kg} / \mathrm{m}^{2}$. Anthropometric measurements were conducted by trained researchers.

\section{Follow-up}

Follow-up measurements would be conducted once a year for 4 years, which would still include the questionnaire for the parents, food diary recording and anthropometric assessment. Regular contact with participants would be made to maintain them in the cohort. The demographic features of subjects who have returned the questionnaires in each follow-up would be compared with baseline data to calculate the loss to follow-up and examine potential attrition bias. 


\section{Distal determinant factors}

\begin{tabular}{|c|c|}
\hline $\begin{array}{c}\text { Mechanism to } \\
\text { promote healthy } \\
\text { eating, e.g, } \\
\text { policies, guidelines }\end{array}$ & $\begin{array}{r}\text { Action competency } \\
\text { on diet and nutrition }\end{array}$ \\
\hline $\begin{array}{c}\text { Engagement of } \\
\text { different } \\
\text { stakeholders }\end{array}$ & $\begin{array}{r}\text { Community } \\
\text { resources to } \\
\text { support healthy } \\
\text { eating }\end{array}$ \\
\hline
\end{tabular}

Intermediate determinant factors

Action competency on

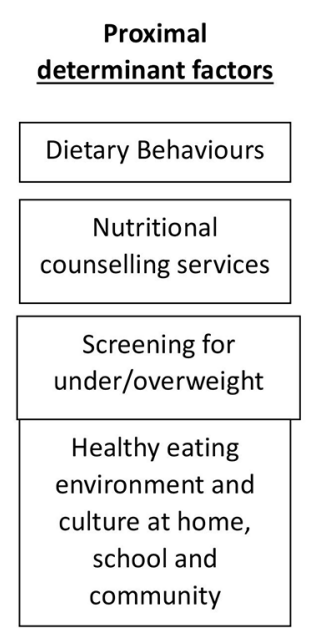

Figure 1 Research model to study nutrition and health.

\section{Pilot study}

To ensure the quality of the cohort study, a pilot study had been conducted to test the logistics and reliability of the selected instruments in the questionnaire. Three kindergartens, involving parents of 104 children, were invited for the pilot study. ${ }^{50} 51$

The parents were invited again to fill in some of the instruments in 2 weeks' time, and the intraclass correlations were computed to examine the test-retest reliability of the instruments. ${ }^{52}$ The test-retest reliability of most questions was higher than 0.7 , which were suitable for administration in the main study.

A subsample of 19 parents filled in the food diary instrument with food photos provided.$^{50}$ The numbers of foods reported in the food diary and in the photos were compared. Out of the 19 parents, 16 of them achieved a high consistency between food diary and food photos (over $90 \%$ of the food items matched).

On completion of the pilot study, the procedure was revised in case of any logistical flaws. Modification or revision of the instruments was conducted, the details of which were recorded before the start of the main phase of the cohort study.

\section{Data collection}

\section{Questionnaire and anthropometric assessment}

The questionnaire was verified for completeness by the student helpers with nutrition backgrounds, and parents were contacted by phone for any missing information. An Excel database (Microsoft excel 2010) was created based on the questionnaire, into which data were entered according to a predefined coding scheme. ${ }^{53}$ Height and weight were entered to the database, and BMI was computed thereafter. The research assistant would conduct data cleaning regularly by computing the frequency figures for each question to identify problematic values. ${ }^{53}$

Cross-checking the problematic values within the questionnaire would be conducted. The research assistant would also periodically perform random checking of the entered data to ensure high data quality.

\section{Food diary}

Food diary records would be checked by a registered dietitian and trained students with nutrition background for any missing or unclear details. Data would be coded and entered into the Food Processor program (V.11.0.137) for analysis.

\section{Data analysis}

The frequency and percentage would be computed for items with categorical or ordinal responses, whereas the mean and SD would be computed for items with continuous responses. For each instrument, the composite score would be calculated. Bivariate correlation would be computed to examine the correlation between the instruments. Independent t-test or analysis of variance would be used to examine the difference of scores by demographic and other variables. Linear and logistic regression would be used to examine the association between those predictive factors and the outcomes. Generalised estimating equations will be used to ascertain the longitudinal changes of the outcomes. The analysis will be conducted using IBM SPSS Statistics V.24.

Dietary data would be analysed using the Food Processor program (V.11.0.137) and Hong Kong food composition mation available, food composition tables for the USA, China, Taiwan, Japan, Singapore and Australia would be used. Food composition tables for Hong Kong are accessible from the Centre for Food Safety, HKSAR (www.cfs. gov.hk/english/nutrient/index.shtml), which contain nutrient data of commonly consumed food items in Hong Kong. As for the dietary data obtained in food diaries, the portion of food reported was initially validated by comparing the reported amount of food during the 3 days with the food photos received for the corresponding day.

The quality of diet would be assessed by the HEI, one of the most extensively studied indices that evaluate the conformance to dietary guidelines and the dietary quality. ${ }^{46}$ The dietary guidelines component in the HEI will be adapted to the Hong Kong standards for preschoolers. Steps to tables. In case of food items with no local nutritional infor- 
calculate the HEI scores will include: (A) identifying the set of foods under consideration (foods consumed by Hong Kong preschoolers); (B) determining the amount of each relevant food group, subgroup and nutrient in the set of foods; (C) deriving the ratios of the scores; and (D) scoring each component (adequacy of total fruit, whole fruit, total vegetables, greens and beans, whole grains, dairy, total protein foods, seafood and plant proteins and fatty acids; moderation of refined grains, sodium and empty calories) using the corresponding standard. ${ }^{46}$

The calculated index score would be compared among subjects, and the associations with health-related outcomes such as growth and weight status would be explored. The adequacy of dietary intake (namely, energy, protein, total fat, carbohydrates, sodium and calcium) would be assessed by comparing the nutrient intake of the subjects with the Chinese dietary reference intakes developed by the Chinese Nutrition Society, as well as the estimated average requirement and the reference nutrient intake from the WHO Food and Agricultural Organization (WHO/FAO) ${ }^{43}{ }^{44}$ The daily intake of the five food groups would be computed and compared with local recommended intakes for children aged 2-6 years.

\section{Long-term growth status}

To assess the growth of our subjects longitudinally, the internationally acceptable definition was adopted. ${ }^{54-56}$ The reference was derived from six large nationally representative cross-sectional growth studies including the USA, Hong Kong and Singapore. Age-specific and sex-specific cut-off points would be used to identify children who are underweight, overweight or obese. ${ }^{54-56}$ For example, at the age of 2 years, the cut-off points for overweight are 18.41 for boys and 18.02 for girls, while at the age of 3 years, the cut-off points are 17.89 for boys and 17.56 for girls.

\section{FINDINGS TO DATE}

By the end of the baseline study recruitment (February 2016), 5273 parents of the children aged 2-4 years from 180 kindergartens and nurseries randomly selected from the 11 districts in Hong Kong have agreed to participate in this study by returning the signed consent form. A total of 3223 subjects have completed and returned the questionnaires. The data entry of the questionnaire was just completed. Table 1 has provided the basic demographic features of the participants. The majority of the participating children were 3 years old $(74.5 \%)$. Mothers were the most common caregiver of the children (95.1\%). A total of $39.0 \%$ parents breast fed their children at early stages, and then fed with formula milk. Vegetables rejection was the most common picky eating habit $(26.2 \%)$.

\section{Strengths and limitations}

The results of the Studying Impact of Nutrition on Growth (SING) study will provide the backbone information of the dietary and nutritional intake of children in Hong Kong. With the information, we can compare their energy intake to the recommendation by the WHO/FAO. In a cross-sectional study in 2010 involving 1272 children aged from 6 months to 4 years old, ${ }^{57}$ three findings are noteworthy: $2.7 \%$ of the participating children were overweight or obese, that their the mean energy intake was found to be close to or above the WHO EAR for energy and their protein intake was adequate. However, the shortcoming was that the cross-sectional design does not enable an examination of the longitudinal changes and the casual effect relationship between early-life nutritional intake and childhood obesity. Therefore, the SING study will be crucial to fill the research gap. In addition, we will develop an HEI applicable to the local population. The SING study will also provide insights into the correlation between suboptimal growth and nutrition status and factors such as dietary patterns, parenting skills, health literacy of parents, household environment and sub optimal breast feeding. It would facilitate the development of a research model to study nutrition and health that incorporates more distal determinant factors (figure 1).

The strengths of the study include the use of cluster sampling and a reasonably large sample size, so the results can be generalised to the Hong Kong population. In addition, most instruments adopted in the study are validated and have been widely used in the literature. One of the limitations of the study is that the breastfeeding practice was self-reported at least 2 years after childbirth; hence, recall bias would be inevitable. Another potential limitation is the lack of serum biomarkers to verify the dietary data. Moreover, the data quality of food diary entries may vary with the education level of parents. Despite these disadvantages, our study will provide a comprehensive view on the food consumption of Hong Kong children and their health status at the present.

Collaborators Resources have not been forthcoming for providing open access to our data at the present, but we welcome collaboration from interested groups. In order to obtain information on data sharing, we invite researchers to contact us at alee@cuhk.edu.hk

Contributors WWST and AL prepared the first draft of manuscript. AL, WWST, CKC, VMK and LWM designed the protocol including the selection or refinement of measuring tools. CKC and KL were involved in pilot testing and are involved in ongoing data collection and analysis. $\mathrm{AL}$ is the principal investigator of the project overseeing the conduct of the study, whereas WWST is the second principal investigator overseeing the data management. CKC is the coordinator of field work.

Funding The study is supported by Wyeth Nutrition in the form of a research grant to the university in accordance to university regulation and guidelines on research. The funding bodies are not involved in data collection and data analysis.

Competing interests None declared.

Ethics approval This study has been approved by the Joint Chinese University of Hong Kong and New Territory East Cluster Clinical Research Ethics Committee (CREC Ref No: 2013-632).

Provenance and peer review Not commissioned; externally peer reviewed.

Data sharing statement The study has just commenced. The corresponding author can be contacted for data if needed.

Open Access This is an Open Access article distributed in accordance with the Creative Commons Attribution Non Commercial (CC BY-NC 4.0) license, which permits others to distribute, remix, adapt, build upon this work non-commercially, and license their derivative works on different terms, provided the original work is 
properly cited and the use is non-commercial. See: http://creativecommons.org/ licenses/by-nc/4.0/

(c) Article author(s) (or their employer(s) unless otherwise stated in the text of the article) 2017. All rights reserved. No commercial use is permitted unless otherwise expressly granted.

\section{REFERENCES}

1. Barker DJ. Sir Richard Doll Lecture. Developmental origins of chronic disease. Public Health 2012;126:185-9.

2. Bhutta ZA. Early nutrition and adult outcomes: pieces of the puzzle. Lancet 2013;382:486-7.

3. Brisbois TD, Farmer AP, McCargar LJ. Early markers of adult obesity: a review. Obesity Reviews 2012;13:347-67.

4. Jones G. Early life nutrition and bone development in children. Nestle Nutr Workshop Ser Pediatr Program 2011;68:227-33. discussion 233-6.

5. Paparo L, di Costanzo M, di Scala C, et al. The influence of early life nutrition on epigenetic regulatory mechanisms of the immune system. Nutrients 2014;6:4706-19.

6. Chan KA, Tsoulis MW, Sloboda DM. Early-life nutritional effects on the female reproductive system. J Endocrinol 2015;224:45-62.

7. Warner JO. Early life nutrition and allergy. Early Hum Dev 2007:83:777-83.

8. Brisbois TD, Farmer AP, McCargar LJ. Early markers of adult obesity: a review. Obes Rev 2012;13:347-67.

9. Lillycrop KA, Burdge GC. Breast cancer and the importance of early life nutrition. Cancer Treat Res 2014:159:269-85.

10. Winzenberg T, Shaw K, Fryer J, et al. Effects of calcium supplementation on bone density in healthy children: meta-analysis of randomised controlled trials. BMJ 2006;333:775-8.

11. McCarthy EK, Kiely M. Vitamin D and muscle strength throughout the life course: a review of epidemiological and intervention studies. $J$ Hum Nutr Diet 2015;28:636-45.

12. Lim SS, Vos T, Flaxman AD, et al. A comparative risk assessment of burden of disease and injury attributable to 67 risk factors and risk factor clusters in 21 regions, 1990-2010: a systematic analysis for the global burden of disease study 2010. Lancet 2012;380:2224-60.

13. Adair LS, Fall CH, Osmond $\mathrm{C}$, et al. Associations of linear growth and relative weight gain during early life with adult health and human capital in countries of low and middle income: findings from five birth cohort studies. Lancet 2013;382:525-34.

14. Stettler N, lotova V. Early growth patterns and long-term obesity risk. Curr Opin Clin Nutr Metab Care 2010;13:294-9.

15. Perng W, Haij H, Belfort MB, et al. Birth size, early life weight gain, and midchildhood cardiometabolic health. $J$ Pediatr 2016;173:122-30.

16. Hales CN, Ozanne SE. The dangerous road of catch-up growth J Physiol 2003;547:5-10.

17. Ong KK. Catch-up growth in small for gestational age babies: good or bad? Curr Opin Endocrinol Diabetes Obes 2007;14:30-4.

18. Wang G, Walker SO, Hong X, et al. Epigenetics and early life origins of chronic noncommunicable diseases. J Adolesc Health 2013;52:14-21.

19. Lee A, Keung VM, Cheung GC. Compensation consumption of high-energy-density food among pre-school children leading to suboptimal intake of recommended food groups: case study in Hong Kong. Public Health 2013:127:182-5.

20. Lee A, Gibbs SE. Neurobiology of food addiction and adolescent obesity prevention in low- and middle-income countries. J Adolesc Health 2013;52:39-42.

21. Skinner JD, Bounds W, Carruth BR, et al. Predictors of children's body mass index: a longitudinal study of diet and growth in children aged 2-8 y. Int J Obes Relat Metab Disord 2004;28:476-82.

22. Arredondo EM, Elder JP, Ayala GX, et al. Is parenting style related to children's healthy eating and physical activity in Latino families? Health Educ Res 2006;21:862-71.

23. Rhee KE, Lumeng JC, Appugliese DP, et al. Parenting styles and overweight status in first grade. Pediatrics 2006;117:2047-54.

24. Lai KW, McBride-Chang C. Suicidal ideation, parenting style, and family climate among Hong Kong adolescents. Int J Psychol Res 2001:36:81-7.

25. Leung CY-W, McBride-Chang C, Lai BP-Y. Relations among materna parenting style, academic competence, and life satisfaction in Chinese early adolescents. J Early Adolesc 2004;24:113-43.

26. Shek DT. A longitudinal study of parenting and adolescent adjustment in Chinese adolescents with economic disadvantage. Int $J$ Adolesc Med Health 2003;15:39-49.
27. Shek DT. Adolescents' perceptions of paternal and maternal parenting styles in a Chinese context. J Psychol 1998;132:527-37.

28. Shek DT. Parenting characteristics and parent-adolescent conflict: a longitudinal study in the Chinese culture. J Fam Issues 2002;23:189-208.

29. Kayaba K. Overcoming the difficulties of cohort studies. J Epidemiol 2013;23:156-7.

30. Leung GM, My N, Wong PT, et al. Cohort Profile: FAMILY Cohort. Int $J$ Epidemiol 2015:dyu257.

31. Lam TH, Leung GM, Ho LM. The effects of environmental tobacco smoke on health services utilization in the first eighteen months of life. Pediatrics 2001;107:e91.

32. Lam WW, Fielding R, McDowell I, et al. Perspectives on family health, happiness and harmony $(3 \mathrm{H})$ among Hong Kong Chinese people: a qualitative study. Health Educ Res 2012;27:767-79.

33. Lee PH, Stewart SM, Lun VM, et al. Validating the concord index as a measure of family relationships in China. J Fam Psychol 2012;26:906-15.

34. Nan H, Lee PH, Ni MY, My N, et al. Effects of depressive symptoms and family satisfaction on health related quality of life: the Hong Kong FAMILY study. PLoS One 2013;8:e58436.

35. Hui LL, Schooling CM, Leung SS, et al. Birth weight, infant growth, and childhood body mass index: Hong Kong's children of 1997 birth cohort. Arch Pediatr Adolesc Med 2008;162:212-8.

36. Leung GM, Ho LM, Lam TH. Secondhand smoke exposure, smoking hygiene, and hospitalization in the first 18 months of life. Arch Pediat Adolesc Med 2004;158:687-93.

37. Hui LN, EA S. Dietary characteristics of Hong Kong young children: Implications for nutrition education Hong Kong. J Pediatr 2006;11:8.

38. Department of Health, Working Group on Diet and Physical Activity. Diet, physical activity and health: hong kong situation. Hong kong: Hong Kong Special Administratrive Region Government, 2012.

39. Gordis L. Epidemiology. 4th ed. Philadelphia: Elsevier/Saunders, 2009.

40. von Elm E, Altman DG, Egger M, et al. The strengthening the reporting of observational studies in epidemiology (STROBE) statement: guidelines for reporting observational studies. J Clin Epidemiol 2008;61:344-9.

41. Scheaffer RL, Mendenhall W, Ott L. Elementary survey sampling. 6th ed. Southbank,Vic; Belmont, Calif: Thomson Brooks/Cole, 2006.

42. Bureau E. Profile of kindergartens and kindergarten-cum-child care centers, 2012.

43. Burlingame $B$, Nishida $C$, Uauy R, et al. Fats and fatty acids in human nutrition: introduction. Ann Nutr Metab 2009;55:5-7.

44. Nishida C, Martinez Nocito F, Nocito FM. FAO/WHO scientific update on carbohydrates in human nutrition: introduction. Eur J Clin Nutr 2007:61:1-4.

45. Society CN. Chinese dietary reference intakes (Chinese DR/s). (Chinese Edition): Chinese Nutrition Society, 2014.

46. Guenther PM, Casavale KO, Reedy J, et al. Update of the healthy eating index: HEl-2010. J Acad Nutr Diet 2013;113:569-80.

47. Department of Health. Concerted efforts for promoting breastfeeding: Department of Health, 2012. (Press Release 28 July 2012).

48. Huus K, Ludvigsson JF, Enskär K, et al. Exclusive breastfeeding of Swedish children and its possible influence on the development of obesity: a prospective cohort study. BMC Pediatr 2008;8:42.

49. Education-Bureau. Issues related to the supply and demand of kindergarten places. Secondary Issues related to the supply and demand of kindergarten places. $2013 \mathrm{http}: / / \mathrm{www}$. legco.gov.hk/yr1314/chinese/panels/ed/papers/ed1028cb4-80-1-c.pdf.

50. Lancaster GA, Dodd S, Williamson PR. Design and analysis of pilot studies: recommendations for good practice. J Eval Clin Pract 2004;10:307-12.

51. Kottner J, Streiner DL. Internal consistency and cronbach's $\alpha$ : comment on Beeckman et al. (2010). Int J Nurs Stud 2010;47:926-8.

52. Yen M, Lo LH, Lh L. Examining test-retest reliability: an intra-class correlation approach. Nurs Res 2002:51:59-62.

53. Williams A. How to write and analyse a questionnaire. J Orthod 2003;30:245-52

54. Cole TJ, Bellizzi MC, Flegal KM, et al. Establishing a standard definition for child overweight and obesity worldwide: international survey. BMJ 2000;320:1240-3.

55. Cole TJ, Flegal KM, Nicholls D, et al. Body mass index cut offs to define thinness in children and adolescents: international survey. BMJ 2007;335:194.

56. Leung SS, Lau JT, Tse LY, et al. Weight-for-age and weight-for-height references for Hong Kong children from birth to 18 years. J Paediatr Child Health 1996;32:103-9.

57. Woo J, Chan R, Li L, et al. A survey of infant and young child feeding in Hong Kong: diet and nutrient intake. Hong Kong SAR: Department of Health, 2012. 